\title{
CONHECIMENTOS E ESPECIFICIDADES DO JOGO NA PRODUÇÃO ACADÊMICO-CIENTIIFICA NA ÁREA DA EDUCAÇÃO/EDUCAÇÃO FÍSICA
}

Recebido em: 26/01/2019

Aceito em: 27/10/2019

\author{
Claube Camile Soares Lima ${ }^{1}$ \\ João Francisco Magno Ribas ${ }^{2}$ \\ Universidade Federal de Santa Maria (UFSM) \\ Santa Maria - RS - Brasil \\ Pierre Normando Gomes-da-Silva ${ }^{3}$ \\ Universidade Federal da Paraíba (UFPB) \\ João Pessoa - PB - Brasil \\ Raquel Valente de Oliveira ${ }^{4}$ \\ Universidade Federal do Rio Grande do Sul (UFRGS) \\ Porto Alegre - RS - Brasil \\ Bruno Minuzzi Lanes 5 \\ Universidade Federal de Santa Maria (UFSM) \\ Santa Maria - RS - Brasil
}

RESUMO: A pesquisa objetivou analisar a concepção de Jogo na produção acadêmicocientífica da área da Educação/Educação Física, bem como seus conhecimentos e especificidades relevantes. Para isso, realizou-se uma revisão bibliográfica, na qual foi identificada a concepção de Jogo presentes em cinco dissertações/teses selecionadas: Jogo para o desenvolvimento das crianças na visão construtivista; com relação de gênero e sexualidade; para o desenvolvimento mental de crianças; Jogo Tradicional e a cultura de povos e gerações; relação com a tecnologia (jogos eletrônicos). Dessa forma,

\footnotetext{
${ }^{1}$ Graduada em Pedagogia pela Universidade Federal de Santa Maria; Especialista em Educação Física Escolar pela Universidade Federal de Santa Maria; Mestre em Educação Física pela Universidade Federal de Santa Maria.

${ }^{2}$ Licenciado em Educação Física pela Universidade Federal de Santa Maria; Mestre em Educação Física pela Universidade Estadual de Campinas; Doutor em Educação Física pela Universidade Estadual de Campinas; Pós-doutor pelo Institut Nacional d'Educació Física de Catalunya. Professor associado do Centro de Educação Física e Desportos, na Universidade Federal de Santa Maria.

${ }^{3}$ Licenciado em Educação Física pelo Centro Universitário de João Pessoa; Mestre em Educação pela Universidade Federal da Paraíba; Doutor em Educação pela Universidade Federal do Rio Grande do Norte; Pós-doutor em Educação Física pela Universidade Federal de Santa Maria; Professor titular do Centro de Ciências da Saúde, na Universidade Federal da Paraíba.

${ }^{4}$ Licenciada em Educação Física pela Universidade Federal de Santa Maria; Mestre em Educação Física pela Universidade Federal de Santa Maria; Doutoranda em Ciências do Movimento Humano pela Universidade Federal do Rio Grande do Sul.

${ }^{5}$ Licenciado em Educação Física pela Universidade Federal de Santa Maria; Mestre em Educação Física pela Universidade Federal de Santa Maria.
} 
o Jogo consiste em um processo composto por variadas características apresentadas em dimensões teórica, metodológica e pedagógica, discutidas e conceituadas no campo acadêmico da área.

PALAVRAS-CHAVE: Jogos Recreativos. Criança. Educação/Educação Física.

\section{GAME KNOWLEDGE AND SPECIFICITIES IN THE ACADEMIC- SCIENTIFIC PRODUCTION IN THE AREA OF EDUCATION/PHYSICAL EDUCATION}

ABSTRACT: The research aims to analyze the conception of Game in the academicscientific production of the Education/Physical Education area, as well as its relevant knowledge and specificities. For this, a bibliographical review was carried out, in which the Game conception was identified in five selected dissertations/theses: Game for the development of children in the constructivist vision; with relation of gender and sexuality; for the mental development of children; Traditional Game and culture of peoples and generations; relation to technology (electronic games). In this way, the Game consists of a process composed of varied characteristics presented in theoretical, methodological and pedagogical dimensions, discussed and conceptualized in the academic field of the area.

KEYWORDS: Games Recreational. Child. Education/Physical Education.

\section{Introdução}

Na Europa, no início do século XIX, surgiram as primeiras instituições de atendimento à criança, baseadas em modelos muito distintos dos atuais, em que seus projetos serviam aos interesses políticos, econômicos e religiosos da população. Esses ambientes foram desenvolvidos pela necessidade social desse período histórico momento do desenvolvimento industrial - em que prevalecia o pensamento de criar espaços para filhos de trabalhadores que representavam um peso financeiro às paróquias, por não apresentar produtividade ao sistema. (MÉSZÁROS, 2008). Por conseguinte, a visão que se tem da criança atualmente é algo historicamente construído, por isso é possível perceber os grandes contrastes em relação ao sentimento de infância no decorrer dos tempos. 
De um ser sem importância, quase imperceptível, atualmente, a criança ocupa lugar de destaque na sociedade, em que a humanidade lhe lança um novo olhar e um novo significado social. Segundo Áries (1978, p. 99), “o sentimento de infância não significa o mesmo que afeição pelas crianças corresponde à consciência da particularidade infantil, essa particularidade que distingue essencialmente a criança do adulto". Nessa perspectiva, o reconhecimento relaciona-se a compreensão da criança, a sua essência enquanto ser, o seu modo de agir e pensar que se diferencia do adulto, e, portanto, merece um olhar mais específico. Atualmente, a criança é vista como um sujeito de direitos, situado historicamente e que precisa ter as suas necessidades físicas, cognitivas, psicológicas, emocionais e sociais supridas, caracterizando um atendimento integral e integrado da criança.

Como um dos conteúdos pertencentes à Educação Física escolar e peculiar da educação infantil, o Jogo configura-se como um objeto de pesquisa de diversos autores da área. Sendo assim, torna-se necessário destacar como essa manifestação cultural vem sendo abordada por alguns autores e como eles defendem a concepção de Jogo, suas características e as possibilidades de uso nas aulas.

Com isso, Marin e Ribas (2013, p. 11) caracterizam o Jogo como:

[...] a lâmpada maravilhosa de Aladim: de suas regras poderão nascer magníficas cenas coletivas, ricas em cores, sempre renovadas, que vão colocar em relação uma multidão de jogadores entusiasmados. Como por mágica, um pequeno punhado de regras lúdicas é capaz de criar um universo vivo em que os atores vão inventar uma dinâmica de interação alegre e frequentemente movimentada.

Rocha (2002) dedica esforços para delimitar e consolidar o campo chamado de Pedagogia da Educação Infantil e Pedagogia da Infância, onde o foco é a própria criança, sua constituição como ser humano no mundo, nos mais diferentes contextos de 
inserção, sua própria cultura e suas capacidades, desde intelectuais até emocionais. Já Kunz (2015) caracteriza o Jogo como forma de expressão, de criação inusitada, de inserção no mundo e como relação original da criança com o mundo em que vive.

Para Huizinga (2007, p. 33), o Jogo é “uma atividade ou ocupação voluntária, exercida dentro de certos e determinados limites de tempo e espaço, segundo regras livremente consentidas, mas absolutamente obrigatórias, dotado de um fim em si mesmo". Esse autor tem como objetivo, em suas pesquisas, analisar o Jogo como um elemento da cultura, presente na vida dos seres humanos, mostrando que devemos compreendê-lo como algo maior, reconhecendo no Jogo o seu significado social e cultural. Huizinga (2007) ainda destaca as características do Jogo, a partir das quais o lúdico se manifesta. Logo conceitua o termo como:

[...] uma atividade livre, conscientemente tomada como "não séria" e exterior à vida habitual, mas ao mesmo tempo capaz de absorver o jogador de maneira intensa e total. É uma atividade desligada de todo e qualquer interesse material, com a qual não se pode obter qualquer lucro, praticada dentro de limites espaciais e temporais próprios, segundo certa ordem e certas regras (p. 16).

A partir deste pressuposto, pode-se afirmar que os jogos infantis podem apresentar algum tipo de competição e regras pré-determinadas, porém o que predomina em sua essência é a relação e a interação dos sujeitos, em que suas regras são flexíveis de acordo com as necessidades e intenção daqueles que nele atuam. Para a melhor compreensão dessas relações, Gomes-da-Silva (2012) aponta a ligação estabelecida entre o Jogo, o brincar e a criança, destacando que quando a criança está imersa no Jogo, perde a noção de tempo, pois, ao estar entregue inteiramente nesse contexto lúdico, ela se encontra em seu próprio tempo e espaço, em um constante agir comunicativo, seja sozinho ou coletivamente, inerente ao ato de brincar. 
Para a Pedagogia da Corporeidade, o Jogo é uma construção sociocultural, provida de sentido, uma forma de fala, organizada pela interação dos sucessivos gestos, vividos num tempo de realização do ser que brinca. (GOMES-DA-SILVA, 2011). Ainda de acordo com esse autor, o brincar é uma condição existencial, própria dos humanos, criado quando estabelecemos um modo divertido de habitar o tempo, de interagir com o meio, que se constitui numa experiência de realização. O Jogo e o brincar estão presentes em todas as épocas até os dias atuais e não permanecem exatamente os mesmos, mas como uma manifestação da cultura popular, uma vez que possuem a função de perpetuar a cultura infantil ou ainda impregnar culturalmente a criança. (BROUGÈRE, 1995).

Neste sentido, entende-se que, além das demais fases da vida, o Jogo está significativamente presente na vida da criança. Ao compreender o Jogo e valorizá-lo como um dos conteúdos que constituem o currículo da Educação Física na educação infantil (BRASIL, 2018), cada vez mais se estará incentivando-o no contexto escolar, para que não seja diminuída sua prática por motivos de espaço e tempo, o que deixariam as crianças distantes de vivenciarem ou ter a oportunidade de experimentar as variadas brincadeiras e Jogos.

No contexto escolar, o Jogo proporciona às crianças o contato a partir das aulas de Educação Física, permitindo o ensino e a aprendizagens de até mesmo outras diferentes práticas corporais que podem estar presentes no ambiente escolar e/ou no dia a dia dos alunos, mas sempre com fim em si mesmo, como um conteúdo específico e particular. Kunz (2017, p. 62) corrobora com isso ao destaca que:

[...] o brincar livre e espontâneo deve ser um conteúdo a ser seguido e valorizado [...]. O brincar assume aqui o centro de um pensar a Pedagogia para as crianças, pois se brinca quando se vive o presente, e 
a Educação Física destaca-se neste contexto por preocupar-se com o maior desejo expressivo da criança, seu movimento/brincadeira.

Partindo da intencionalidade deste estudo, no que tange a compreensão do Jogo enquanto manifestação corporal, esta pesquisa tem como objetivo analisar a concepção de Jogo na produção acadêmico-científica da área da Educação/Educação Física, bem como seus conhecimentos e especificidades relevantes.

\section{Metodologia}

Para atingir o objetivo proposto, buscou-se aprofundamento teórico acerca do conhecimento de Jogo por meio de uma revisão bibliográfica, a partir de pesquisas anexadas no banco de teses e dissertações da Coordenação de Aperfeiçoamento de Pessoal de Nível Superior (CAPES) e no Núcleo Brasileiro de Dissertações e Teses (NUTESES). Essa busca foi realizada em trabalhos científicos nacionais, publicados em dois dos estados da região sul do país: Rio Grande do Sul e Santa Catarina. Para isso, limitaram-se três Instituições de Ensino Superior para cada estado, conforme a sequência: Universidade Federal do Rio Grande do Sul (UFRGS), Universidade Federal de Santa Maria (UFSM), Universidade Federal de Pelotas (UFPEL), Universidade Federal de Santa Catarina (UFSC), Universidade do Estado de Santa Catarina (UDESC) e Universidade do Sul de Santa Catarina (UNISUL), nas quais foram selecionadas por possuírem pós-graduação em Educação e Educação Física e por serem as principais Instituições de Ensino Superior dos respectivos estados. Em ambos os portais online (Portal CAPES e NUTESES), utilizou-se dos descritores “Jogo, Infância, Educação Física e Ensino".

Salienta-se que o estado do Paraná não foi considerado para esta pesquisa em decorrência da ausência de trabalhos nas referidas áreas quando relacionados à temática 
no recorte que se estabeleceu para a análise. Vale ainda destacar que a escolha por pesquisas realizadas apenas em instituições do sul do país se deu pelos pesquisadores pertencerem a essa região, e, portanto, apresentarem maior afinidade e conhecimento acerca dos jogos culturalmente construídos nesse território. Além disso, por se tratar do entendimento da concepção de Jogo, julgou-se necessário ampliar os horizontes teóricos em relação a essa prática corporal abordada pelo estudo. Ao realizar essa delimitação metodológica valorizou-se a cultura da região sul e o papel que essas instituições de ensino exercem na produção cientifica da Educação/Educação Física brasileira.

Já no que diz respeito à metodologia do estudo, utilizou-se de uma abordagem de cunho teórico, apoiada em análise da pesquisa qualitativa, na qual se trata de conhecer e evidenciar o conhecimento científico sobre o tema que vem sendo publicado em obras acadêmicas e documentos oficiais. Nessa perspectiva, Richardson (1999, p. 102) destaca que o objetivo da pesquisa qualitativa "não reside na produção de opiniões representativas e objetivamente mensuráveis de um grupo; está no aprofundamento da compreensão de um fenômeno social por meio de análises qualitativas". Severino (2007, p. 122) corrobora com isso ao afirmar que:

\begin{abstract}
A pesquisa bibliográfica é aquela que se realiza a partir do registro disponível, decorrente de pesquisas anteriores, em documentos impressos, como livros, artigos, teses, etc. Utiliza-se de dados ou de categorias teóricas já trabalhadas por outros pesquisadores e devidamente registrados. Os textos tornam-se fontes dos temas a serem pesquisados. O pesquisador trabalha a partir das contribuições dos autores dos estudos analíticos constantes dos textos.
\end{abstract}

A importância da pesquisa de cunho teórico/bibliográfico está em aprofundar elementos que posteriormente poderão ser analisados de forma mais prática e concreta. Ao explorar dados teóricos o pesquisador apropria-se do conhecimento de forma aprofundada, estabelecendo e sistematizando novas diretrizes relacionadas a temática 
estudada. Para corroborar com essa ideia, Demo (2009) advoga que a pesquisa de cunho teórico/bibliográfico consiste em elucidar a relevância de distintos conhecimentos, além de possibilitar a reconstrução de teorias a partir de outras teorias, sendo possível obter uma maior qualidade de dados para posteriores intervenções.

A partir disso, entende-se que realizar um apanhado geral sobre o campo a ser estudado permite ao pesquisador apresentar frutos da produção científica acerca da temática pesquisada. Esse procedimento valoriza a produção de conhecimento, bem como permite maior apropriação e compreensão por parte do leitor do que vem sendo difundido na pesquisa científica da área.

Desse modo, realizou-se a revisão bibliográfica com o intuito de buscar as produções (dissertações e teses) dos especialistas da comunidade acadêmica, tendo como foco central desse procedimento a análise das concepções referente ao Jogo. Para isso, foram delimitados os estudos publicados no período de 2012 a 2016, recorte temporal que abrange os últimos cinco anos até a elaboração desta pesquisa. A seguir, dispõem-se das figuras que expressam o número de trabalhos encontrados em cada ano, Instituição de Ensino e em cada um dos estados.

Figura 1: Dados referentes às dissertações e teses das Instituições de Ensino Superior (IES) - RS

\begin{tabular}{|c|c|c|c|c|c|c|c|}
\hline \multicolumn{7}{|c|}{ RIO GRANDE DO SUL } \\
\hline IES & $\begin{array}{c}\text { Total de } \\
\text { registros } \\
\text { encontrados }\end{array}$ & 2012 & 2013 & 2014 & 2015 & 2016 & $\begin{array}{c}\text { Total - } \\
\mathbf{2 0 1 2} \text { a } \\
\mathbf{2 0 1 6}\end{array}$ \\
\hline UFRGS & 361 & 9 & 4 & 3 & 2 & 3 & $\mathbf{2 1}$ \\
\hline UFSM & 97 & 0 & 0 & 2 & 1 & 1 & $\mathbf{4}$ \\
\hline UFPEL & 26 & 0 & 0 & 2 & 1 & 0 & $\mathbf{3}$ \\
\hline
\end{tabular}


Fonte: Elaborada pelos autores.

Figura 2: Dados referentes às dissertações e teses das Instituições de Ensino Superior (IES) - SC

\begin{tabular}{|c|c|c|c|c|c|c|c|}
\hline \multicolumn{7}{|c|}{ SANTA CA TARINA } \\
\hline IES & $\begin{array}{c}\text { Total de } \\
\text { registros } \\
\text { encontrados }\end{array}$ & 2012 & 2013 & 2014 & 2015 & 2016 & $\begin{array}{c}\text { Total - } \\
\mathbf{2 0 1 2} \mathbf{a} \\
\mathbf{2 0 1 6}\end{array}$ \\
\hline UFSC & 313 & 0 & 1 & 3 & 2 & 6 & $\mathbf{1 2}$ \\
\hline UDESC & 49 & 0 & 1 & 0 & 0 & 0 & $\mathbf{1}$ \\
\hline UNISUL & 17 & 0 & 0 & 0 & 0 & 0 & $\mathbf{0}$ \\
\hline
\end{tabular}

Fonte: Elaborada pelos autores.

Como destacado nas figuras acima, após a busca realizada nos dois portais online com os descritores “Jogo, Infância, Educação Física e Ensino”, obteve-se um número expressivo de pesquisas sobre a referida temática, quando não delimitadas por ano de publicação: 361 na UFRGS; 97 na UFSM; 26 na UFPEL; 313 na UFSC; 49 na UDESC e 17 na UNISUL. Após esse processo de busca, restringiu-se àquelas publicadas entre o período pré-determinado - 2012 a 2016. Posteriormente a leitura detalhada dos resumos dessas pesquisas e tendo em vista os objetivos deste estudo, selecionou-se, para a leitura na íntegra, um total de cinco pesquisas, sendo três dissertações e duas teses, onde quatro delas são de Instituições de Ensino Superior do estado do Rio Grande do Sul e uma do estado de Santa Catarina.

Tendo como pressuposto os critérios adotados quanto à seleção destas produções, na figura abaixo, encontra-se disposto o detalhamento das cinco pesquisas selecionadas e analisadas integralmente, com seu respectivo autor, título do trabalho, Instituição, ano, tipo de publicação e palavras-chave. 
Figura 3: Informações acerca das Dissertações e Teses selecionadas

\begin{tabular}{|c|c|c|c|c|}
\hline AUTOR & TÍTULO & $\begin{array}{l}\text { INSTITUIÇÃO } \\
\text { E ANO DE } \\
\text { PUBLICAÇÃO }\end{array}$ & $\begin{array}{c}\text { TIPO DE } \\
\text { PUBLICAÇÃO }\end{array}$ & $\begin{array}{l}\text { PALAVRAS- } \\
\text { CHAVE }\end{array}$ \\
\hline $\begin{array}{l}\text { MOLOZZI, } \\
\text { BRUNA }\end{array}$ & $\begin{array}{c}\text { O jogo do } \\
\text { conhecimento no dia- } \\
\text { a-dia da Educação } \\
\text { Infantil }\end{array}$ & UFRGS - 2012 & Dissertação & $\begin{array}{l}\text { Epistemologia } \\
\text { genética; Jogo; } \\
\text { Educação Infantil. }\end{array}$ \\
\hline $\begin{array}{l}\text { PRESTES, } \\
\text { LILIANE } \\
\text { MADRUGA }\end{array}$ & $\begin{array}{l}\text { Enredadas na rede: } \\
\text { jogos para crianças } \\
\text { (re) produzindo } \\
\text { relações desiguais de } \\
\text { gênero }\end{array}$ & UFRGS - 2014 & Tese & $\begin{array}{c}\text { Cibercultura; Gênero; } \\
\text { Infância; Jogo; } \\
\text { Sexualidade. }\end{array}$ \\
\hline $\begin{array}{l}\text { PINHEIRO, } \\
\text { SILVIA } \\
\text { NARA } \\
\text { SIQUEIRA }\end{array}$ & $\begin{array}{c}\text { O jogo com regras } \\
\text { explicitas pode ser } \\
\text { um instrumento para } \\
\text { o sucesso de } \\
\text { estudantes com } \\
\text { história de fracasso } \\
\text { escolar }\end{array}$ & UFPEL - 2014 & Tese & $\begin{array}{c}\text { Jogo; Fracasso } \\
\text { escolar; } \\
\text { Aprendizagem; } \\
\text { Funções psicológicas } \\
\text { superiores; Psicologia } \\
\text { Histórico-cultural. }\end{array}$ \\
\hline $\begin{array}{l}\text { SILVA, } \\
\text { SABRINE } \\
\text { DAMIAN }\end{array}$ & $\begin{array}{c}\text { Jogos tradicionais } \\
\text { organizados no } \\
\text { estado do Rio Grande } \\
\text { do Sul: uma } \\
\text { aproximação } \\
\text { etnomotriz }\end{array}$ & UFSM - 2015 & Dissertação & $\begin{array}{c}\text { Jogo Tradicional; } \\
\text { Praxiologia Motriz; } \\
\text { Grupo social. }\end{array}$ \\
\hline $\begin{array}{l}\text { MARTINS, } \\
\text { PATRICIA } \\
\text { NUNES }\end{array}$ & $\begin{array}{c}\text { As imagens no design } \\
\text { de jogos educativos: } \\
\text { uma experiência com } \\
\text { o jogo saga dos } \\
\text { conselhos }\end{array}$ & UFSC - 2016 & Dissertação & $\begin{array}{c}\text { Imagem; Jogo } \\
\text { eletrônico } \\
\text { educacional; Design } \\
\text { de game; } \\
\text { Experiência. }\end{array}$ \\
\hline
\end{tabular}

Fonte: Elaborada pelos autores.

\section{Resultados e Discussão}

Tendo em vista a intenção do procedimento metodológico deste estudo, cujo objetivo foi analisar as concepções de Jogo nas produções acadêmicas das principais Instituições de Ensino Superior dos estados do Rio Grande do Sul e de Santa Catarina, torna-se possível apresentar os principais resultados acerca dos cinco trabalhos selecionados. Sendo assim, a dissertação de Molozzi (2012), publicada na UFRGS, teve como foco de pesquisa o estudo do Jogo no contexto da sala de aula na educação 
infantil. Esse estudo foi fundamentado com base teórica na Epistemologia Genética de Jean Piaget (1978), em que aborda a gênese do Jogo, caracterizando três tipos de jogo infantil: jogos de exercícios, jogos simbólicos e jogos de regras.

Piaget investiga a natureza e a gênese do conhecimento nos processos e estágios de desenvolvimento da criança, abordando a importância da reflexão e do pensar infantil. Molozzi (2012) realizou sua pesquisa em uma escola privada do município de Porto Alegre - RS, com um grupo de alunos de educação infantil. A metodologia utilizada foi através do método clínico: observação das ações dos sujeitos em uma determinada situação, alicerçada em Jean Piaget que também utilizou desse método, com o intuito de observar seus filhos e teorizar sobre o desenvolvimento da criança. A autora utilizou recursos como filmagens do grupo de crianças em situações que envolviam variados tipos de Jogos (jogos livres, em grupo). A concepção de Jogo para Molozzi (2012) aparece como uma situação lúdica, não necessariamente ligada a um sistema de regras previamente definidas ou a algum material específico. A autora destaca que esta situação lúdica só se define no momento em que os jogadores a assumem como tal, em função de seus sentimentos e impressões.

Neste sentido, o objetivo da pesquisa de Molozzi (2012) foi descobrir quais materiais promovem um maior desafio às crianças. Para isso, a autora apresentou novas propostas de Jogo para o grupo de crianças em sala de aula, observando como cada uma joga, como compartilham (ou não) os materiais durante o jogo, as situações que ocorrem, como demonstram interesse no jogo proposto, etc., descrevendo as situações e ações por elas realizadas. A partir disso, concluiu-se que os Jogos na sala de aula possuem características construtivistas no desenvolvimento das crianças, ao extrair deles aprendizagem e conhecimento para sustentar a própria prática no contexto escolar. 
(MOLOZZI, 2012). Ainda, constatou-se que o Jogo proporciona à criança construir e reconstruir suas opiniões e ideias sobre o mundo, ampliando a percepção de si mesmo e dos outros, tornando-se possíveis protagonistas de suas próprias ações. Para os resultados apontados na pesquisa de Molozzi (2012), destaca-se a relevância da observação das ações das crianças em momentos de Jogo, pois possibilita ao professor deduzir sobre a etapa de desenvolvimento em que a criança se encontra, possibilitando uma prática mais adequada às necessidades de cada uma.

A partir disso, foi possível constatar que a autora do estudo analisado considera o Jogo como um meio de desenvolver os aspectos psicológicos da criança. Observa-se, assim, uma limitação no entendimento dessa manifestação cultural que se constitui numa prática social humana, com grande valor social e cultural para a criança. Com isso, entende-se que a prática pedagógica do professor deve ser ampliada para os aspectos que atribuem ao Jogo um importante valor cultural que deve ser apropriado pela criança.

A Tese de Prestes (2014) se intitula "Enredadas na rede: jogos para crianças (re) produzindo relações desiguais de gênero" e teve como objetivo investigar os conteúdos veiculados em sites de Jogos que se autodeclaram como voltados ao público infantil, especialmente aqueles voltados às meninas. Nessa pesquisa, ancorada nos estudos da Pedagogia de gênero e sexualidade, com base na sociologia e políticas públicas, a autora mapeou sites considerados preferidos por um grupo de crianças. Posteriormente a isso, foi realizada a análise dos conteúdos contidos nos mesmos, além do mapeamento das pesquisas, estudos, reportagens e bibliografia sobre o assunto. Prestes (2014) utilizou de questionários semiestruturados, preenchidos por 196 crianças dos anos iniciais do Ensino Fundamental de uma escola da periferia de Porto Alegre - 
RS. Desse total, foram analisados 105 questionários, sendo 52 meninas e 53 meninos, na faixa etária de 08 a 10 anos.

No decorrer do estudo, a autora buscou problematizar o resultado da pesquisa, uma vez que entre as crianças participantes, $45 \%$ revelaram que os primeiros contatos com a internet ocorreram entre 03 a 04 anos de idade, sendo esse o mesmo percentual daquelas que aprenderam sozinhas a navegar na rede. Quanto ao tempo de acesso diário, cerca de 30\% delas afirmaram que não possuíam limite de horários, ficando diariamente mais de seis horas na internet. Durante esse tempo, as crianças revelaram que acessam jogos, sites de relacionamento, salas de bate-papo, "baixavam" arquivos de música, vídeos, etc. Dentre as atividades mais realizadas, os jogos foram os favoritos, sendo citados por $85 \%$ dos/as entrevistados/as. Entretanto, os sites de jogos acessados por meninos e meninas possuíam conteúdos diferenciados e a escolha era feita a partir dos interesses e por indicação de colegas.

Desta forma, Prestes (2014), entende que o conceito de gênero está relacionado fundamentalmente aos significados atribuídos a ambos os sexos em contextos históricos e culturais diversos. Em relação à expressão Jogo, a mesma nos conduz a reflexão acerca das concepções de gênero presentes em tal categorização, ou seja, ela nos remete a uma concepção essencialista de gênero ao especificar conteúdos distintos para meninas e, consequentemente, para os meninos. (PRESTES, 2014). Por fim, os resultados dessa pesquisa apontaram a necessidade de que os debates em torno do acesso das crianças à internet sejam ampliados no âmbito das políticas públicas, bem como no âmbito das famílias e demais instituições responsáveis pela educação infantil.

A partir da análise realizada sobre este estudo, foi possível verificar uma despreocupação com o debate do "se movimentar", como é apresentado por Kunz 
(2017). O trabalho não discute os limites necessários para os jogos digitais na infância e, tão pouco, mostra a necessidade do jogo presencial, corporal e lúdico, possibilidade que vem perdendo espaço para os jogos digitais no cotidiano e que, no contexto escolar, deveria ser mais enfatizado e vivenciado na educação infantil.

A pesquisa de Pinheiro (2014), realizada na UFPEL, buscou responder a seguinte indagação: O Jogo com regras explícitas pode ser um instrumento para o sucesso de estudantes com história de fracasso escolar? Para isso, a autora teve como base as ideias de Vygotsky, Leontiev e Elkonin, autores filiados à Psicologia Históricocultural. A metodologia utilizada foi de caráter qualitativo e baseada em intervenções estruturadas em três momentos: avaliação inicial e avaliação final junto aos alunos, mães e professoras e, por último, intervenções por meio dos jogos "memória", "cara a cara" e "damas".

Pinheiro (2014) utilizou como instrumentos para coleta dos dados, entrevistas semiestruturadas, análise documental (histórico escolar e boletim acadêmico), observação, Teste de Desempenho Escolar (TDE), subtestes de informação e a Escala de Inteligência Wechsler para Crianças. A partir disso, a autora concluiu que as intervenções obtiveram sucesso e que a aprendizagem, mediante a prática dos Jogos, promoveu o desenvolvimento das funções psicológicas superiores (FPS) e isso se refletiu no desempenho escolar dos estudantes. Também foi constatado que os efeitos em relação ao Jogo com regras explícitas constituem-se em um caminho para desnaturalizar o fracasso e alcançar o sucesso escolar.

O grande avanço da pesquisa, na perspectiva da autora, foi comprovar que o fracasso não deve e não pode ser naturalizado, principalmente em crianças provenientes de classes economicamente desfavorecidas. Portanto, a concepção de Jogo para Pinheiro 
(2014) aparece como um "mediador" eficiente entre a aprendizagem e o desenvolvimento dos sujeitos que tinham histórias de fracasso escolar. Os dados coletados durante as intervenções sugerem que o Jogo com regras explícitas, por meio da mediação, criou zonas de desenvolvimento proximal, gerando desenvolvimento cognitivo e emocional, ratificando as ideias de Vygotsky (2008).

A dissertação de Silva (2015) objetivou estudar os Jogos tradicionais organizados no estado do Rio Grande do Sul. A análise da autora teve como metodologia uma pesquisa documental, pautando-se na perspectiva teórica da Praxiologia Motriz, conhecimento da Educação Física. Como o estudo propôs realizar uma análise praxiológica dos Jogos tradicionais, foram desconsiderados os brinquedos e os jogos de mesa, pois neles a "participação dos jogadores não é enfatizada pelo movimento". (MARIN; RIBAS, 2013, p. 30). Isso se justifica pelo fato de que a Praxiologia Motriz propõe "estudar a ação especificamente motriz, ou seja, [...] a que se concentra na intervenção do corpo”. (PARLEBAS, 2001, p. 356).

Assim, a cultura lúdica pesquisada neste estudo, contabilizou um total de 44 Jogos tradicionais no estado do Rio Grande do Sul. A concepção de Jogo atribuída por Silva (2015) que, por sua vez, embasa-se na perspectiva de Parlebas, idealizador da Praxiologia Motriz, reconhece como Jogo tradicional aquele "enraizado frequentemente em uma longa tradição cultural, que não tenha sido regulamentado por instituições oficiais”. (PARLEBAS, 2001, p. 286). Sendo assim, no Jogo tradicional, o sistema de regras constitui a matriz fundamental e fica a cargo da cultura local a transmissão de seus códigos e rituais, normalmente transmitidos de geração para geração. As distintas características apresentadas em relação aos grupos sociais quanto à expressividade de alguns elementos da lógica externa, mostraram que cada grupo social, mesmo 
localizado dentro do mesmo estado, apresenta características que são peculiares de cada grupo, de cada cultura que envolve os Jogos. (SILVA, 2015).

A partir do olhar deste estudo, que valoriza uma manifestação corporal da Educação Física que apresenta escassez de conhecimento científico, entende-se que o Jogo tradicional, como manifestação que apresenta fortes impressões locais ou regionais, deve ser sistematizado pedagogicamente para que os aspectos históricos e valores locais sejam retomados e refletidos. Não basta, mais uma vez, reproduzirmos as vivências corporais sem retomarmos os elementos éticos e estéticos dessa manifestação corporal. Por conseguinte, o Jogo tradicional carrega com maior intensidade as impressões da cultura local quando é problematizado pedagogicamente e revisado no processo educacional.

Por fim, como a última pesquisa analisada, tem-se a dissertação de Martins (2016), realizada na UFSC e intitulada “As imagens no design de jogos educativos: uma experiência com o jogo saga dos conselhos". Para o percurso teórico, foi abordada as relações existentes entre as tecnologias, os jogos eletrônicos e a educação, incluindo uma ampliação sobre o conceito de inteligência e enfatizando o projeto do jogo eletrônico como possibilidade de seu desenvolvimento. Para isso, a autora adotou como base para fundamentação, a Teoria das Inteligências Múltiplas. (GARDNER, 1995). Já no que tange à metodologia, foram realizadas entrevistas e aplicados questionários a cursistas, tendo como referência a análise de conteúdo.

Os resultados encontrados apontam para a influência das "imagens" e dos "aspectos visuais interativos" com a experiência dos jogadores, o que tende a contribuir para a identificação e a sensação de satisfação durante a aprendizagem, direcionando a atenção do jogador para os objetivos do Jogo. (MARTINS, 2016). Nos referidos relatos 
obtidos pelos instrumentos de pesquisa, também foram destacados aspectos emocionais em relação ao personagem, na interação e na condução dos feedbacks durante os Jogos.

Por meio das imagens utilizadas para a elaboração da pesquisa (minijogos, labirintos e mapas), os Jogos foram relacionados aos conteúdos estudados, revisados de forma lúdica e interativa, o que proporcionou a construção de sua identidade. Para tanto, essas imagens aproximaram o Jogo de seu público alvo, quando cenários, personagens e elementos interativos referenciam visualmente aspectos do universo escolar aos quais os conteúdos estão relacionados. (MARTINS, 2016).

Com o pressuposto de investigar a concepção de Jogo na Educação/Educação Física, bem como seus conhecimentos e especificidades, constatou-se que nas interfaces das dissertações e teses selecionadas e analisadas neste estudo, é possível fazer aproximações entre o Jogo e as atividades de ensino. Sendo assim, o Jogo para Molozzi (2012) possui o foco no contexto da sala de aula da educação infantil, baseado na teoria construtivista de Piaget, em que se preocupa com o desenvolvimento nos processos de estágio da criança, buscando compreensão através de observações das ações propostas para um determinado grupo. Dessa forma, concluiu-se que os Jogos em sala de aula possuem características construtivistas no desenvolvimento das crianças, o que contribui para a prática pedagógica de professores que se encontram alinhados com a teoria construtivista.

Relacionando com o estudo de Prestes (2014), esse também apresenta o Jogo para crianças, porém com o olhar direcionado a relação de gênero e sexualidade, voltados a conteúdos em site de Jogos para meninos e meninas. A autora problematiza como os educadores devem portar-se mediante os novos desafios que a mídia constantemente impõe e que reflete diretamente nas práticas educacionais. $\mathrm{Na}$ tese de 
Pinheiro (2014), a autora adotou como base a teoria de Vygotsky, acreditando que o Jogo possa ser um caminho para o desenvolvimento mental, o que repercutirá no desempenho escolar do estudante que apresenta dificuldades em termos de aprendizagem, abordando a partir da Teoria Histórico-cultural a importância do Jogo para o desenvolvimento psíquico do ser humano.

Já Silva (2015) fundamentou-se na perspectiva teórica da Praxiologia Motriz, voltada para área da Educação Física, onde apontou também aspectos relevantes de diferentes gerações e idades no que diz respeito aos Jogos tradicionais. A autora finalizou seu estudo destacando importantes temas que carecem de aprofundamento e novas pesquisas, como: mercadorização, esporte espetáculo, individualismo, marketing esportivo, sociedade capitalista, gênero e políticas públicas. Tais pesquisas lançam o olhar sobre o conhecimento do Jogo dirigido à infância, aos brinquedos, às brincadeiras, aos jogos eletrônicos e aos Jogos tradicionais. Já Martins (2016), fundamentada na Teoria das Inteligências Múltiplas, abordou a significativa relação estabelecida entre o Jogo e a tecnologia, ou seja, os chamados jogos eletrônicos, utilizando, para isso, imagens e aspectos visuais interativos que corroboraram para o desenvolvimento de sua referida pesquisa.

Com base nestas produções acadêmicas, pode-se afirmar que os Jogos, enquanto manifestações culturais, também atuam pedagogicamente, desde que amparados, mediados, discutidos e refletidos sobre o sentido social e pedagógico atribuído a este. Cabe salientar que, independentemente da base teórica, as dissertações e teses analisadas apresentam significativas semelhanças, no que tange a preocupação com o desenvolvimento e aprendizagem da criança e a importância da presença do Jogo para as mesmas, considerando os conhecimentos e especificidades que o Jogo propõe. 
A partir deste pressuposto, salienta-se a necessidade de estudos que sustentem e apresentem elementos pedagógicos mais concretos em pesquisas de mestrado e doutorado, no que tange ao Jogo como manifestação corporal que enfatize o brincar, conforme propõem Surdi; Mello e Kunz (2015, p. 469):

O brincar, como possuidor de um valor em si mesmo, constitui uma realidade própria. Por isso, quando estamos brincando, envolvemo-nos de tal forma na atividade que ela própria nos satisfaz por inteiro. Doamo-nos por completo, e é exatamente nesse momento que percebemos muito do que realmente somos e da capacidade que temos. Nosso eu se revela através da realização de atividades significativas que oportunizam o conhecimento de si através das formas de se relacionar com o mundo.

Ainda, faz-se necessário destacar que é de suma importância que o professor tenha conhecimento de que o Jogo varia conforme o contexto que se encontra, podendo diferenciar-se por seus objetivos, regras, meio social e cultural, e também pela forma como é conduzido em seu processo de ensino, seja ele formal ou informal. Durante a realização deste estudo, constatou-se, alicerçado nas produções analisadas, que o Jogo possui características importantes e distintas, entre elas a liberdade da ação, pelo fato de ser permitido praticá-lo de diferentes maneiras, respeitando o desejo dos participantes e tendo como essência o divertimento e a ludicidade. Quanto a seu contexto educacional, para que não se perca a essência do Jogo, cabe ao professor respeitar e considerar suas características, proporcionando a seus alunos atividades de aprendizagem por meio lúdico (brincar/jogar).

\section{Considerações Finais}

O Jogo consiste em um processo composto por variados significados e características apresentadas em diferentes dimensões teóricas, metodológicas e pedagógicas que vem sendo constantemente discutidas e conceituadas no campo 
acadêmico. Por isso, o presente estudo teve por intuito analisar a concepção de Jogo na produção acadêmico-científica da área da Educação/Educação Física, bem como seus conhecimentos e especificidades relevantes.

Neste sentido, concluiu-se que a cultura do Jogo se apresenta como construção social, bem como patrimônio histórico e cultural da humanidade que precisa ser experienciada e vivenciada em um determinado tempo e espaço, levando em consideração sua importância no desenvolvimento da criança. Além disso, ele deve proporcionar a ludicidade e a interação entre seus participantes, buscando o ensino e a aprendizagem de forma significativa, proporcionando o conhecimento de si, do outro e do mundo. Com isso, busca-se desenvolver a criticidade de crianças e jovens, para que sejam pessoas ativas e reflexivas mediante a sociedade em que estiverem inseridas.

Sendo assim, pôde-se constatar a relevância dessa temática tanto para o campo acadêmico quanto para o contexto escolar, uma vez que as produções analisadas abordaram e discutiram diferentes conhecimentos em relação ao Jogo, cujos conhecimentos, especificidades e concepções variam de acordo com seu contexto. Contudo, em relação ao foco de investigação desta pesquisa, observou-se que ainda há poucos estudos no universo do Jogo como conteúdo para a infância/educação infantil, uma vez que foram encontradas somente três dissertações e duas teses em dois dos estados da região sul do país que se referiam ao tema da pesquisa, o que aponta a necessidade de ampliação e aprofundamento na produção científica dessa manifestação corporal.

\section{REFERÊNCIAS}

ÁRIES, P. História Social da Criança e da Família. Rio de Janeiro: LTC, 1978.

BRASIL. Ministério da Educação. Base Nacional Comum Curricular. Brasília, 2018. Disponível em: https://basenacionalcomum.mec.gov.br/a-base. 
BROUGÈRE, G. Brinquedo e Cultura. São Paulo: Cortez, 1995.

DEMO, P. Pesquisa e construção de conhecimento: metodologia científica no caminho de Habermas. Rio de Janeiro: Tempo Brasileiro, 2009.

GARDNER, H. Inteligências múltiplas: a teoria na prática. Tradução Maria Adriana Veríssimo Veronese. Porto Alegre: Artes Médicas, 1995.

GOMES-DA-SILVA, P.N. A corporeidade do movimento: por uma análise existencial das práticas corporais. In: HERMIDA, J.F.; ZOBOLI, F. (Orgs.). Corporeidade e Educação. João Pessoa: Editora Universitária UFPB, 2012. p. 139-174.

. A cultura do jogo e o jogo da cultura: por uma semiótica da corporeidade. João Pessoa: Editora Universitária UFPB, 2011.

HUIZINGA, J. Homo Ludens: o jogo como elemento da cultura. 5. ed. São Paulo: Perspectiva, 2007.

KUNZ, E. Brincar e Se-movimentar: tempos e espaços da vida da criança. Ijuí: Unijuí, 2017.

. Educação Física - Ensino e mudanças. 3. ed. Ijuí: Unijuí, 2015.

MARIN, E.C.; RIBAS, J.F.M. Jogo tradicional e cultura. Santa Maria: Editora UFSM, 2013.

MARTINS, P.N. As imagens no design de jogos educativos: uma experiência com o jogo saga dos conselhos. 2016. 183f. Dissertação (Mestrado em Educação) Universidade Federal de Santa Catarina, Florianópolis, 2016.

MÉSZÁROS, I. A educação para além do capital. São Paulo: Boitempo, 2008.

MOLOZZI, B. O jogo do conhecimento no dia-a-dia da Educação Infantil. 2012. 73f. Dissertação (Mestrado em Educação) - Universidade Federal do Rio Grande do Sul, Porto Alegre, 2012.

PARLEBAS, P. Juegos, deporte y sociedad: léxico de Praxiología Motriz. Barcelona: Paidotribo, 2001.

PIAGET, J. A formação do símbolo na criança: imitação, jogo e sonho, imagem e representação. 3. ed. Rio de Janeiro: Guanabara Koogan, 1978.

PINHEIRO, S.N.S. O jogo com regras explícitas pode ser um instrumento para o sucesso de estudantes com história de fracasso escolar? 2014. 219f. Tese (Doutorado em Educação) - Universidade Federal de Pelotas, Pelotas, 2014.

PRESTES, L.M. Enredadas na rede: jogos para crianças (re) produzindo relações desiguais de gênero. 2014. Tese (Doutorado em Educação) - Universidade Federal do Rio Grande do Sul, Porto Alegre, 2014. 
RICHARDSON, R.J. Pesquisa social: métodos e técnicas. 3. ed. São Paulo: Atlas, 1999.

ROCHA, E.A.C. Infância e educação: delimitações de um campo de pesquisa. Educação, Sociedade e Culturas, Porto, v. 17, p. 67-88, 2002.

SEVERINO, A.J. Da epistemologia à técnica: Metodologia do trabalho científico. 23. ed. São Paulo: Cortez, 2007.

SILVA, S.D. Jogos tradicionais organizados no estado do Rio Grande do Sul: uma aproximação etnomotriz. 2015. 185f. Dissertação (Mestrado em Educação Física) Universidade Federal de Santa Maria, Santa Maria, 2015.

SURDI, A.C.; MELO, J.P.; KUNZ, E. O brincar e o se-movimentar nas aulas de educação física infantil: realidades e possibilidades. Movimento, Porto Alegre, p. 459$470,2015$.

VYGOTSKY, L.S.A brincadeira e o seu papel no desenvolvimento psíquico da criança. Tradução Zoia Prestes. Revista Virtual de Gestão de Iniciativas Sociais, Rio de Janeiro, p. 23-36, 2008.

\section{Endereço dos Autores:}

Claube Camile Soares Lima

Avenida Antônio Botega, ${ }^{\circ}$ 588, Bairro São José

Santa Maria - RS - 97.095-030

Endereço Eletrônico: cacaulima2009@yahoo.com.br

João Francisco Magno Ribas

Rua dos Andradas, $\mathrm{n}^{\circ}$ 602, Bairro Bonfim

Santa Maria - RS - 97.010-031

Endereço Eletrônico: ribasjfm@hotmail.com

Pierre Normando Gomes-da-Silva

Campus I - Cidade Universitária

João Pessoa - PB - 58.033-455

Endereço Eletrônico: pierrenormandogomesdasilva@gmail.com

Raquel Valente de Oliveira

ESEFID - UFRGS

Rua Felizardo, $n^{\circ} 750$ - Jardim Botânico

Porto Alegre - RS - 90.690-200

Endereço Eletrônico: raquelvvallente@hotmail.com

Bruno Minuzzi Lanes

Rua Coronel Ernesto Francisco Bertaso, n ${ }^{\circ}$ 6, Bairro São Cristóvão

Chapecó - SC - 89.803-270

Endereço Eletrônico: brunolanes10@hotmail.com 